\title{
Analogies for Teaching Mutant Allele Dominance Concepts
}

\author{
Rebecca L. Seipelt-Thiemann \\ Biology Department, Middle Tennessee State University, Murfreesboro, USA \\ Email: rebecca.seipelt@mtsu.edu
}

Received August $29^{\text {th }}, 2012$; revised September $27^{\text {th }}, 2012$; accepted October $9^{\text {th }}, 2012$

\begin{abstract}
Analogies connect new and familiar concepts and ideas by providing a comfortable and known framework within which students can integrate new concepts. Use of analogies to aid understanding of abstract and/or complex ideas is commonly used in molecular sciences, such as genetics, molecular biology, and biochemistry. Five analogies for different mechanisms of mutant allele dominance, a seemingly counterintuitive idea in genetics, were designed and assessed in an upper division undergraduate/masters level course. Each of the five mechanisms, haploinsufficiency, acquired function, poison product, increased activity, and inappropriate expression, was described in the context of a human disease and molecular mechanism and followed by a descriptive analogy which mirrored the molecular mechanism using real world items or a video clip. The majority of students reported increased interest, understanding, and engagement following the analogies, as well as decreased confusion.
\end{abstract}

Keywords: Analogy; Genetics; Allele Dominance

\section{Introduction}

The constructivist model of learning suggests that students learn by connecting new ideas into an existing framework of knowledge. Analogies are commonly used by students, teachers, and text books to make these connections, particularly where abstract concepts or ideas are involved. Regardless of type, analogies share common features, such as the familiar concept or idea (analog), the new concept or idea (target), elements of similarity between the analog and target (links, features, or attributes), and the mapping of similarities between the target and analog (Glynn, 1995). Even though all analogies share those common features, they vary significantly in their makeup, for example, whether the analog is scientific or non-scientific, whether the analogy is planned or not, whether the analogy is student or teacher-initiated, and whether the analog and target are concrete or abstract (Oliva, Axcarate, \& Navarrete, 2007). It is also important to note that six general elements are considered important for analogy use, but not do not necessarily always follow the same systematic order: 1) target introduction, 2) analog review, 3) feature identifications, 4) analog-target similarity mapping, 5) analogy breakdown, and 6) analogy conclusion (Oliva, Axcarate, \& Navarrete, 2007; Glynn, 2007; Glynn, 2008).

Analogies are used in all levels and subdisciplines in biology, but none so much as in the more abstract areas of genetics, molecular biology, and biochemistry. Indeed, the fact that the term "gene" has many different definitions, depending on historical and scientific context (Gericke \& Hagberg, 2007; Smith \& Adkison, 2010), further complicates both introductory and advanced instruction in these disciplines. Tibell and Rundgren (2010) suggest domain-specific visualization tools will aid in student learning of complex and abstract concepts. Here, five visual and hands-on analogies for use in genetics are described with the aim of helping students gain a greater understanding of a non-intuitive concept, mutant allele dominance.

Dominance and recessiveness are terms used to describe both phenotypes and alleles/genes. However, students generally simply accept the use of the terms without understanding why a mutant allele is considered dominant or recessive or how the alleles actually generate the mutant or normal phenotype. Recessiveness of a mutant allele is more easily understood by students for a number of reasons. First, there is one model explanation for recessiveness; that is, the single wildtype allele in a heterozygote produces sufficient gene product to obtain a "normal" phenotype. Second, this explanation can be extended by the knowledge that most gene products are enzymes, which are not destroyed in a chemical reaction, but continuously convert substrate to the needed cellular product. However, the dominance of a mutant allele in a heterozygote is counter-intuitive since the presence of a single wildtype, functional allele is not sufficient to generate a normal phenotype. Additionally, the interaction of the dominant mutant and the wildtype recessive allele at the molecular level can be very specific to the function of the encoded mutant or wildtype protein. To this end, five general examples explain a large number of valid mechanisms of mutant allele dominance: haploinsufficiency, acquired function, poison product, increased enzyme activity, and inappropriate expression. As these mechanisms are counter-intuitive, an active analogy for each mechanism in connection with a specific human genetic disease was developed and used in the classroom to aid students in understanding these specific molecular mechanisms and thus the mechanisms of mutant allele dominance. Student assessments of the analogies suggest the majority of students are more engaged, have increased understanding, and have decreased confusion.

\section{Study Purpose}

The purpose of this study was to generate and assess teaching 
tools that may enable students to gain an increased understanding of molecular mechanisms of mutant allele dominance.

\section{Procedures and Relevant Descriptions}

First, a verbal and visual description of the dominance mechanism was introduced using one powerpoint slide per mechanism that included a list of symptoms included in the phenotype for a specific human genetic disease, a picture of an affected person, and either a drawing or micrograph of the molecular appearance of the trait. Next, each active analogy discussed in the context of the disease mechanism and then demonstrated to or engaged in by the students. The analogy was linked back to the specific human disease verbally. Students then filled out a short survey asking them to rate their: 1) understanding, 2) engagement, 3) interest, and 4) confusion for each model before the analogy on a scale of $1-5$. The survey asked them to gauge whether these items went "up", "down", or remained the "same" for each model/mechanism. Finally, students were asked to rank the analogies on which helped understanding the most and why.

\section{Mechanism 1: Haploinsufficiency}

The explanation for mutant allele dominance by haploinsufficiency is probably the easiest to understand relative to the recessiveness model since it uses similar reasoning. The idea is that either the wildtype allele produces a minimally active protein or the amount of protein required is so great that the normal phenotype is only generated when both alleles produce functional product.

The human molecular example of haploinsufficiency was Stickler syndrome I (Online Mendelian Inheritance in Man (OMIM) \#108300, 2012). Stickler syndrome I is a dominantly inherited disease caused by mutations in the COL2A1 gene which normally produces a structural protein found in cartilage and the vitreous humor of the eye (Korkko, Ritvaniemi, Haataja, Kaariainen, Kivirikko, Prockop, \& Ala-Kokko, 1993). Heterozygotes exhibit myopia progressing to retinal detachment, among other traits, due to structural defects resulting from insufficient COL2A1 production during development (Richards, Baguley, Yates, Lane, Nicol, Harper, Scott, \& Snead, 2000).

The analogy involved building a structure (collagen) using plastic blocks to represent COL2A1 proteins. Students were given eight lego blocks (COL2A1 proteins) and asked to stack them in sets of two. They were told that four stacks of two were sufficient for the wild-type phenotype (homozygous wild-type, Figure 1(A)). Students were then asked to break down the blocks, remove four of them, mimicking a deletion at one allele (heterozygous, Figure 1(B)). Students were asked to re-stack the blocks in sets of two. Again, four sets were required for a normal phenotype, but were not produced illustrating that at times $50 \%$ production is insufficient for a maintenance of retinal attachment (wildtype phenotype).

\section{Mechanism 2: Acquired Function}

The acquired function explanation for mutant allele dominance involves the mutant allele encoding a protein that has acquired something "extra" and is therefore responsible for the abnormal phenotype. The mutant allele may encode a regulated protein whose control has been lost or the protein may be able
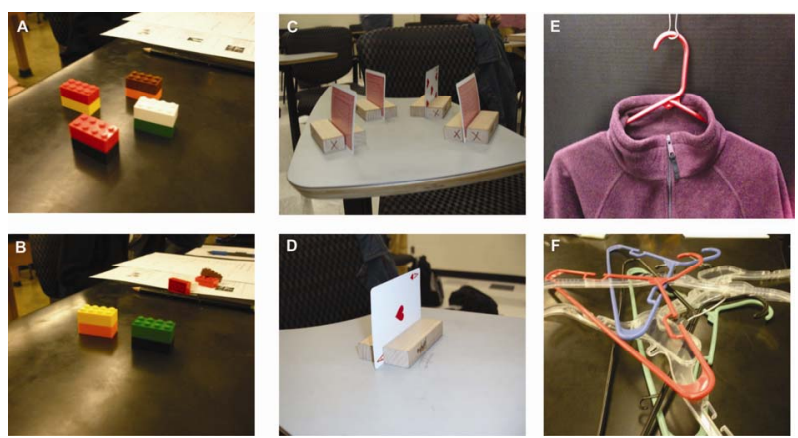

Figure 1.

Examples of Analogy Visuals. (A)-(B) Haploinsufficiency (homozygous wildtype vs. heterozygous); (C)-(D) Poison product (heterozygous before vs. after cellular destruction of "poisoned complexes"; (E)-(F) Acquired function (normal function vs. acquired function).

to perform some alternate function in a different biological pathway or process. In this case, the phenotype may have nothing to do with the normal function of the protein, but instead result from destroying or altering a second, unrelated pathway or process.

The human molecular example of acquired function was sickle cell anemia variant Antilles. Sickle cell anemia can be caused by several different mutations in the beta globin gene (HBB, OMIM \#141900, 2012). One mutation in the beta globin gene, which is dominant, is the HbS Antilles allele (OMIM \#141900.0244, 2012). Wildtype hemoglobin, which is composed of both beta and alpha globin, functions to carry oxygen in red blood cells. This mutation, a change of valine to isoleucine at amino acid 23 (V23I), results in a modified hemoglobin molecule that polymerizes into long rods (Herrick, 1910). These rods deform the normally pliable red blood cell into a rigid sickle-shaped cell. Abnormal red blood cells then occlude tiny capillaries and deprive tissue of necessary oxygen resulting in sickle cell crisis.

The analogy involved creating a structural tangle (Sickle cell rods) using an object with a different known function (a clothes hanger). Students were shown a hanger and asked the function (to hang up clothes, Figure 1(C)). Equal numbers of plastic hangers (wildtype proteins) and wire hangers (HbS proteins) were placed in a sack and shaken to simulate low oxygen tension. This generated a tangle of hangers (Figure 1(D)), mimicking the polymerization of the hemoglobin rods that generate the inflexible, sickle-shaped red blood cell.

\section{Mechanism 3: Poison Product}

The explanation for mutant allele dominance by poison product is probably least intuitive because it involves protein quaternary structure and probability. Generally, one mutant protein in a protein complex initiates the cell's quality control mechanism and destroys the entire protein complex. This results in only $25 \%$ normal protein complexes being present, thus leading to a more severe phenotype than simple allele loss.

The human molecular example of poison product was osteogenesis imperfecta, type II (OMIM \#166210, 2011). Patients with this inherited disease have very brittle bones and severely weakened heart valves that must be monitored closely if the patient survives. This disease is caused by a mutation in the alpha 1 collagen gene, which produces a protein that is a primary building block for structural collagen in bones. The col- 
lagen trimer is composed of two molecules of alpha 1 and one molecule of alpha 2 . In heterozygotes, each trimer can contain no, one, or two mutant alpha 1 molecules; however, only purely wildtype trimers are not degraded by the cell. Therefore, only $25 \%$ of the original trimers are available to build structural integrity, resulting in the brittle bones and weak heart valves observed in the disease (Williams \& Prockop, 1983).

The analogy involved building structures (collagen trimers) using wooden blocks (alpha 1 collagen) and other miscellaneous materials (alpha 2 collagen, Figure 1(E)). Students were given eight small wooden blocks among other items such as crayons and rubberbands. Half of the blocks were marked with an "X" to denote one allele's "worth" of mutant alpha 1 collagen molecules. Students were asked to build four identical structures without looking at the "X" status of the blocks. Students were then asked to destroy all structures containing a mutant alpha 1 molecule (Figure 1(F)). On average one molecule of the four remained in each group, illustrating how production of $50 \%$ mutant alpha 1 collagen molecules could result in only $25 \%$ normal collagen trimers which results in the extremely weakened bones and heart valves observed in osteogenesis imperfecta patients.

\section{Mechanism 4: Increased Enzyme Activity}

The increased enzyme activity explanation for mutant allele dominance was that the enzyme encoded by the mutant allele is more active than the wildtype enzyme and generates too much product in a biochemical reaction or pathway. Build up of the product or shunting the product to a different pathway generates the phenotype.

The human molecular example of increased enzyme activity was hereditary gout. Hereditary gout can be caused by a mutation in the PRPS (phosphoribosylpyrophosphate synthetase gene (OMIM \#300661, 2012). The metabolic/biochemical pathway functions as a certain rate and when PRPS activity increases, the pathway becomes overloaded so that product is shunted to another pathway whose final product is uric acid (Becker, Meyer, \& Seegmiller, 1973). Uric acid crystallizes in the fluid-filled spaces of the joints producing the severe joint pain characterizing gout.

The analogy for increased enzyme activity was illustrated using a film clip freely available on the internet. Students were shown a video clip from the "I Love Lucy" show in which Lucy works in a candy factory (Oppenheimer, Pugh, Carroll, \& Asher, 1952). A reliably available clip of this scene can be found at http://www.youtube.com/watch?v=0YGF5R9i53A (Busciglio, 2010). At normal speed, the candy (the product), is acted upon by people (enzymes) to produce a box of wrapped candy (the final product). However, when the pathway speed is increased, via an upstream overactive enzyme, Lucy is unable to wrap candy pieces and place them back on the conveyor belt. She starts pulling candy off the conveyor belt without wrapping it (buildup of intermediate product), and finally, puts candy in her hat and shirt (shunting the product to an alternate path). This film clip humorously illustrates how alleles for overactive enzymes, such as PRPS in hereditary gout, can produce unnecessary products that generate a phenotype even though a normal allele is also present with the mutant allele.

\section{Mechanism 5: Inappropriate Expression}

The explanation for mutant allele dominance via inappropri- ate expression involves altered control of gene expression rather than production of a mutant protein. A functional protein is expressed, but in the wrong tissue or at the wrong time during development. The presence of the protein and its functionality produces the mutant phenotype.

The human molecular example of inappropriate expression was chronic myeloid leukemia. Chronic myeloid leukemia is caused by a fusion of chromosomes 9 and 22 that puts the ABL oncogene under the control of a BCR locus (OMIM \#608232, 2012). This inappropriate expression of a growth-promoting protein drives proliferation of immune cells generating cancer (De Klein, Van Kessel, Grosveld, Bartram, Hagemeijer, Bootsma, Spurr, Heisterkamp, Groffen, \& Stephenson, 1982).

The analogy for inappropriate expression involved the use of texting-type language in a more formal situation (Table 1). Students were directed to an internet site listing the "texting" version of many common phrases, such as TTYL denotes "talk to you later" and "2moro" for tomorrow. See NetLingo for numerous examples at http://www.netlingo.com/acronyms.php. It was agreed that this type of shorthand is generally acceptable while texting, but then students were asked whether it was appropriate to use these for $50 \%$ of the language (one mutant "texting" allele and one wildtype allele) in a formal paper, such as those assigned in English classes, or on essay questions in exams. This example illustrates how appropriate timing, whether it is expression of proliferation-promoting genes or use of formal language, is critical for a good outcome (normal phenotype or a decent grade).

\section{Extending the Experience}

- Present a genetic disease with a known molecular cause and ask students to make a hypothesis as to whether the mutant allele is dominant or recessive and if dominant, then identify to which mechanism it is most similar.

- Have students categorize known dominant genetic diseases based by mechanism based on molecular information.

- Have students develop their own analogy for each mechanism using different genetic diseases.

\section{Results}

The main objective of this study was to present analogies involving the complex and counter-intuitive mechanisms of mutant allele dominance to the molecular biology education

Table 1.

Selected texting acronyms and their meanings $\mathrm{s}^{\mathrm{a}}$.

\begin{tabular}{cc}
\hline Text speak/Acronym & Meaning \\
\hline addy 4 & address \\
nesec & before \\
ntim & any second \\
ooo & not that it matters \\
ptp & pardon the pun \\
slm & see last mail \\
\hline
\end{tabular}

Note: aPlease see NetLingo at http://www.netlingo.com/acronyms.php/. 


\section{R. L. SEIPELT-THIEMANN}

community for their own use. However, as noted in previous research (Venville \& Treagust, 1997; Orgill \& Bodner, 2004), analogies can be at best helpful, but at least, confusing and/or harmful to the learning experience. To address this issue, the analogies were evaluated by upper division undergraduates and master's students for two cycles of the course (two years). In-

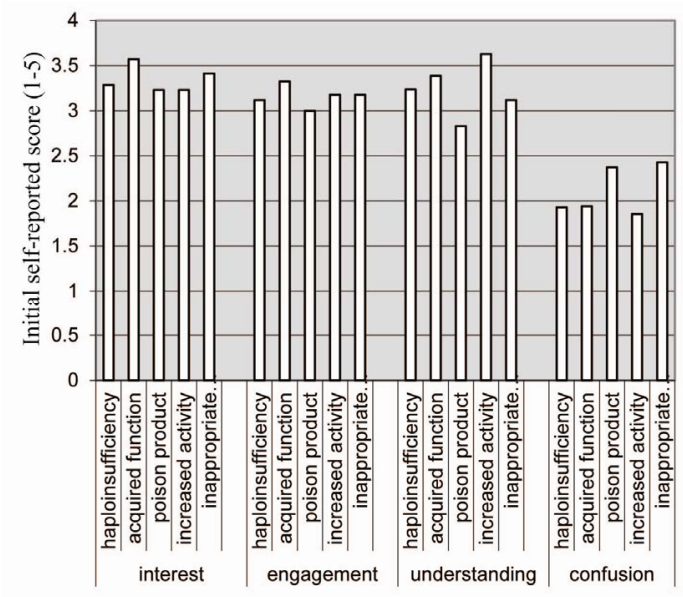

(A) terest, engagement, understanding and confusion were assessed on a Likert scale $(1-5)$ by students prior to the analogy (Figure 2(A)) and the change in interest, engagement, understanding, and confusion was self-reported following the analogies (Figures 2(B) and 3). Pre-analogy interest for all analogies ranged from a mean of 3.23 to 3.57 out of 5 . For engagement, the

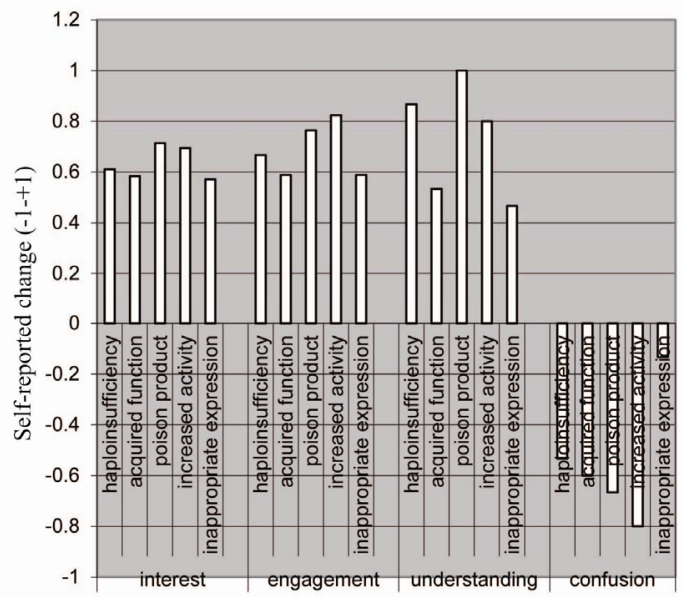

(B)

Figure 2.

Student Assessment. Mean values of interest, engagement, understanding, and confusion relating to allele dominance (A) Prior to analogies. Scoring was $1-5$ with 1 being least and 5 being most and (B) Change following analogies. Scoring was -1 to +1 with -1 indicating decrease, 0 indicating no change, and +1 indicating an increase. $\mathrm{n}=36$.

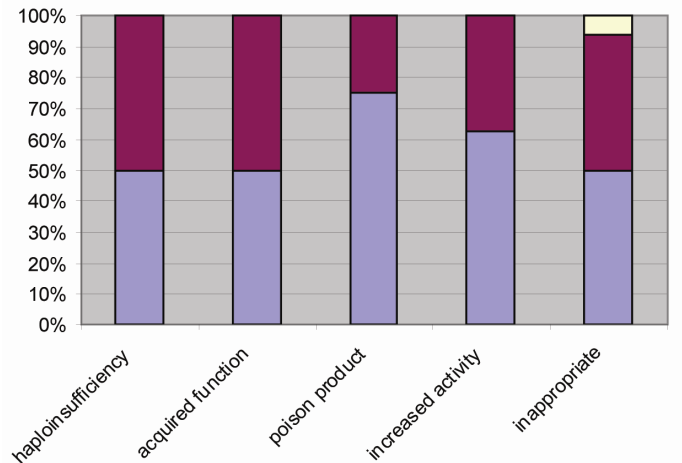

(A)

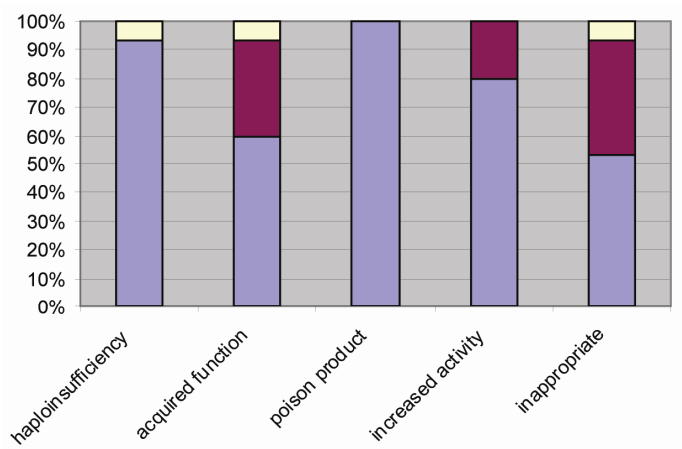

(C)

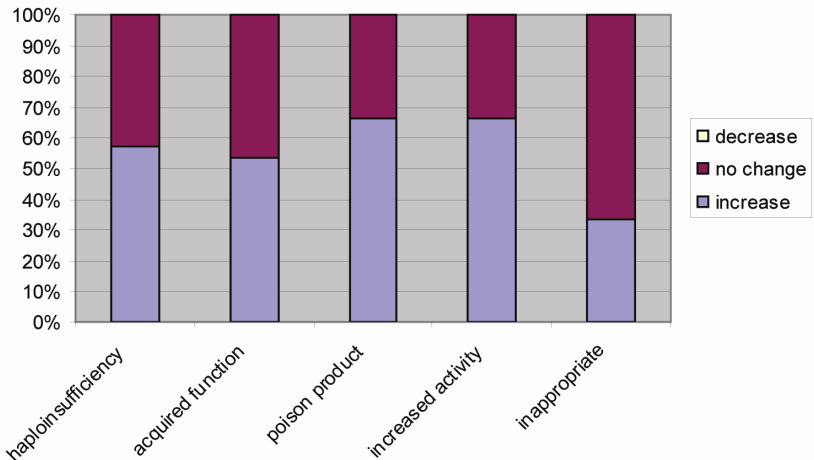

(B)
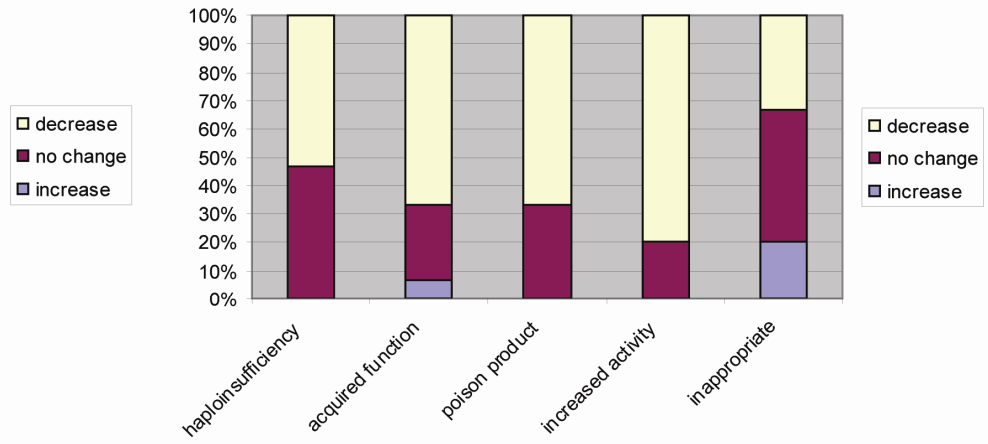

(D)

Figure 3.

Overview of student-reported change following analogies. Student decreases, no changes, and increases are represented as stacked columns showing the proportion or percentage of total students having increased, decreased, and no change in (A) Interest; (B) Engagement; (C) Understanding; and (D) Confusion. $\mathrm{n}=36$. 
average pre-analogy scores ranged from 3.0 to 3.32 . The understanding pre-analogy mean scores had a range of 2.82 to 3.62 . Self-reported confusion prior to analogy for all analogies ranged from 1.85 to 2.43 .

General observations and trends, rather than statistical analyses, are reported here, first because there is little statistical power in small observation samples, and second, it is of interest to observe how individual students within the pool reflected on their own learning and analogy use. To highlight this, the data for change in interest, engagement, understanding, and confusion are presented as stacked columns where each student's response within the pool is visible (Figure 3). Following the analogy, students reported little to no decreases in interest, engagement, or understanding and little to no increases in confusion (Figures 3(A)-(D)). Approximately half of all students noted an increase in interest and engagement for all analogies (Figures 3(A) and (B)), while most students reported an increase in understanding for three of the five analogies (Figure 3(C)). The self-reported change in confusion differed the most of all measurements, with the analogy for inappropriate expression being ranked as least helpful and the analogy for increased activity being rated as most helpful (data not shown).

\section{Discussion}

Science students and teachers commonly use analogies inside and outside the classroom to bridge the gap between an idea they understand and a similar new idea or concept. In particular, analogies for genetics, molecular biology, and biochemistry concepts, which are highly abstract, can benefit students' understanding. The purpose of this project was to construct and evaluate analogies of molecular mechanisms to help gain a greater understanding of mutant allele dominance in human genetic disease. Five analogies for five distinct molecular mechanisms were tested with upper-level undergraduates and masters-level students in two cycles of a human genetics course $(\mathrm{n}=36)$. All were positively reviewed by the majority of students. Extending the experiences with other examples and thought-provoking problems, as noted in the section above, in addition to having students identify areas in which the analogy breaks down, will be helpful to those students who may not have benefited from the initial analogy. These analogies may be particularly useful for those instructors who are moving towards a curriculum that is centered on genetic and phenotypic variation, molecular consequences, and genomics, as proposed for different educational audiences by Dougherty (2009) and Redfield (2012), as they help visually illustrate molecular connections among genes, heterozygosity, biochemistry, genotype, and phenotype in the human.

\section{Acknowledgements and Supplementary Material}

RLST thanks Dr. Michael Rutledge and Ms. Chatoria Kent for their helpful comments. RSLT will gladly share the introductory powerpoint slides. Please contact her by email at rebecca.seipelt@mtsu.edu.

\section{REFERENCES}

Becker, M. A., Meyer, L. J., \& Seegmiller, J. E. (1973). Gout with purine overproduction due to increased phosphoribosyl phosphate synthetase activity. American Journal of Medicine, 55, 232-242. doi:10.1016/0002-9343(73)90174-5
Busciglio, R. (2010). Lucy candy 3.

http://www.youtube.com/watch?v=0YGF5R9i53A

De Klein, A., Van Kessel, A. G., Grosveld, G., Bartram, C. R., Hagemeijer, A., Bootsma, D., Spurr, N. K., Heisterkamp, N., Groffen, J., \& Stephenson, J. R. (1982). A cellular oncogene is translocated to the Philadelphia chromosome in chronic myelocytic leukaemia. $\mathrm{Na}$ ture, 300, 765-767. doi:10.1038/300765a0

Dougherty, M. J. (2009). Closing the gap: Inverting the genetics curriculum to ensure an informed public. The American Journal of $\mathrm{Hu}$ man Genetics, 85, 6-12. doi:10.1016/j.ajhg.2009.05.010

Gericke, N. M., \& Hagberg, M. (2007). Definition of historical models of gene function and their relation to students' understanding of genetics. Science \& Education, 16, 849-881. doi:10.1007/s11191-006-9064-4

Glynn, S. M. (1995). Conceptual bridges: Using analogies to explain scientific concepts. The Science Teacher, 62, 25-27.

Glynn, S. M. (2007). Methods and strategies: The Teaching-withanalogies model. Science and Children, 44, 52-55.

Glynn, S. M. (2008). Making science concepts meaningful to students: Teaching with analogies. In S. Mikelskis-Seifert, U. Ringelband, \& M. Brückmann (Eds.), Four decades of research in science education: From curriculum development to quality improvement (pp. 113125). Münster: Waxmann.

Herrick, J. B. (1910). Peculiar elongated and sickle-shaped red blood corpuscles in a case of severe anemia. Archives of Internal Medicine, 6, 517-521.

Korkko, J., Ritvaniemi, P., Haataja, L., Kaariainen, H., Kivirikko, K. I., Prockop, D. J., \& Ala-Kokko, L. (1993). Mutation in type II procollagen (COL2A1) that substitutes aspartate for glycine alpha-I-67 and that causes cataracts and retinal detachment: Evidence for molecular heterogeneity in the Wagner syndrome and the Stickler syndrome (arthro-ophthalmopathy). The American Journal of Human Genetics, $53,55-61$.

Oliva, J. M., Axcarate, P., \& Navarrete, A. (2007). Teaching models in the use of analogies as a resource in the science classroom. International Journal of Science Education, 29, 45-66. doi:10.1080/09500690600708444

Online Mendelian Inheritance in Man (2012). MIM Number: $\{108300\}$. Baltimore, MD: Johns Hopkins University. URL (last checked 20 January 2012). http://omim.org/

Online Mendelian Inheritance in Man (2012). MIM Number: $\{141900\}$. Baltimore, MD: Johns Hopkins University. URL (last checked 6 June 2012). http://omim.org/

Online Mendelian Inheritance in Man (2011). MIM Number: $\{166210\}$. Baltimore, MD: Johns Hopkins University. URL (last checked 6 October 2011). http://omim.org/

Online Mendelian Inheritance in Man (2012). MIM Number: $\{300661\}$. Baltimore, MD: Johns Hopkins University. URL (last checked 20 April 2012). http://omim.org/

Online Mendelian Inheritance in Man (2012). MIM Number: $\{608232\}$. Baltimore, MD: Johns Hopkins University. URL (last checked 27 July 2012). http://omim.org/

Oppenheimer, J., Pugh, M., Carroll, B. Jr. (Writers), \& Asher, W. (Director) (1952). Job switching [39]. In D. Arnaz (Producer), I love Lucy. Hollywood, CA: Columbia Broadcasting System.

Orgill, M. and Bodner, G. (2004). What research tells us about using analogies to teach chemistry. Chemistry Education: Research and Practice, 5, 15-32.

Richards, A. J., Baguley, D. M., Yates, J. R. W., Lane, C., Nicol, M., Harper, P. S., Scott, J. D., \& Snead, M. P. (2000). Variation in the vitreous phenotype of Stickler syndrome can be caused by different amino acid substitutions in the $\mathrm{X}$ position of the type II collagen Gly-X-Y triple helix. The American Journal of Human Genetics, 67, 1083-1094. doi:10.1086/321189

Redfield, R. J. (2012). "Why do we have to learn this stuff?"-A new genetics for 21 st century students. PLOS Biology, 10, e1001356. doi:10.1371/journal.pbio. 1001356

Smith, M. U., \& Adkison, L. R. (2010). Updating the model definition of the gene in the modern genomic era with implications for instruction. Science \& Education, 19, 1-20. doi:10.1007/s11191-008-9161-7

Tibell, L. E. A., \& Rundgren, C.-J. (2010). Educational challenges of 


\section{R. L. SEIPELT-THIEMANN}

molecular life science characteristics and implications for education and research. CBE Life Sciences Education, 9, 25-33.

doi:10.1187/cbe.08-09-0055

Venville, G. J., \& Teagust, D. F. (1997). Analogies in biology education: A contentious issue. The American Biology Teacher, 59, 282-
287. doi: $10.2307 / 4450309$

Williams, C. J., \& Prockop, D. J. (1983). Synthesis and processing of a type I procollagen containing shortened pro-alpha-1(I) chains by fibroblasts from a patient with osteogenesis imperfecta. The Journal of Biological Chemistry, 258, 5915-5921. 